\title{
Improving access to contraception through integration of family planning services into a multidrug-resistant tuberculosis treatment programme
}

Dr Emily Frances Cornish ${ }^{1}$, Dr Jonathan Hudson ${ }^{2}$, Dr Ross Sayers ${ }^{2}$, Dr Marian Loveday ${ }^{3,4}$

1. Elizabeth Garrett Anderson Institute for Women's Health, University College London (UCL), UK

2. Estcourt Hospital, KwaZulu-Natal, South Africa

3. Health Systems Research Unit, South African Medical Research Council, Durban, KwaZulu-Natal, South Africa

4. Centre for the AIDS Programme of Research in South Africa, Nelson R Mandela School of Medicine, University of KwaZulu-Natal, Durban, South Africa

\section{Corresponding author:}

Dr Emily Frances Cornish BA BMBCh DTM\&H

Postal address: Flat 4, 32 Dalston Lane, London, UK, E8 3AU

Email address: e.cornish@ucl.ac.uk

Telephone: +44 (0) 7732027097

Word count (excluding title page, abstract, figures, references and tables): 1198 


\section{ABSTRACT}

\section{Objectives}

Multidrug-resistant tuberculosis (MDR-TB) is a global public health priority. The advent of the World Health Organisation's Short Course regimen for MDR-TB, which halves treatment duration, has transformed outcomes and treatment acceptability for affected patients. Bedaquiline, a cornerstone of the Short Course regimen, has unknown teratogenicity and the WHO therefore recommends reliable contraception for all female MDR-TB patients in order to secure eligibility for bedaquiline. We were concerned that low contraceptive uptake among female patients in our rural South African MDR-TB treatment programme could jeopardise their access to bedaquiline. We therefore conducted a service delivery improvement project that aimed to audit contraceptive use in female MDR-TB patients, integrate family planning services into MDR-TB care and increase the proportion of female patients eligible for bedaquiline therapy.

\section{Methods}

Contraceptive use and pregnancy rates were audited in all female patients aged 13-50 initiated on our MDR-TB treatment programme in 2016. We then implemented an intervention consisting of procurement of depot-medroxyprogesterone acetate (DMPA) for the MDR-TB unit and training of specialist MDR-TB nurses in administration of DMPA. The audit cycle was repeated for all female patients aged 13-50 initiated on the programme in January-October 2017 (post-intervention).

\section{Results}

The proportion of women on injectable contraceptives by the time of MDR-TB treatment initiation increased significantly in the post-intervention cohort $(77.4 \%$ vs. $23.9 \%$, p <0.0001).

\section{Discussion}

By integrating contraceptive services into our MDR-TB programme we significantly increased contraceptive uptake, protecting women from the obstetric risks associated with pregnancy during MDR-TB treatment and maximising their eligibility for bedaquiline therapy. 


\section{Keywords}

1. Hormonal contraception

2. Long-acting reversible contraception

3. Family planning service delivery

4. Multidrug-resistant tuberculosis

5. Human immunodeficiency virus 


\section{MAIN TEXT}

\section{Background: MDR-TB in South Africa}

Multidrug-resistant tuberculosis (MDR-TB), defined as TB resistant to rifampicin and isoniazid, caused 240,000 deaths in 2016 and poses a major threat to global TB control.[1] The World Health Organisation (WHO) Global Tuberculosis Report categorises South Africa as one of only 14 countries to appear on the high-burden lists for all three of TB, MDR-TB and HIV-TB coinfection. Despite considerable governmental investment in this public health crisis, South Africa continues to have the largest HIV epidemic in the world and the sixth-highest incidence of MDR-TB.[1]

Until the last decade, patients diagnosed with MDR-TB routinely endured up to 24 months of therapy, with inpatient treatment at specialist hospitals for the entire 6-8 month intensive phase. The discovery of nosocomial transmission of extensively-drug-resistant (XDR)-TB within KwaZulu-Natal hospitals in 2006[2] prompted the introduction of decentralised TB programmes, designed to minimise hospital admission. This was reinforced by the 2012 implementation of Xpert MTB/RIF, an automated molecular assay that detects rifampicin resistance in under two hours, after which case detection of MDR-TB more than doubled. The resultant shortage of inpatient beds, coupled with low acceptability of prolonged hospitalisation among patients, led to rising pre-treatment mortality and cemented the major strategic shift towards decentralised care.[3] Under this model, patients are initiated on treatment at nonspecialist district hospitals and continue their follow-up via community clinics, returning for monthly hospital outpatient appointments.

The advent of the WHO Short Course regimen for MDR-TB, which reduces duration from 2024 to 9-12 months, represents the second significant breakthrough in recent years. [4] However, the potential teratogenic effects of certain Short Course medications including bedaquiline, the first new MDR-TB drug to be approved in 40 years, remain unknown. Pregnancy during MDRTB treatment presents a significant risk to mother and fetus in terms of physiological burden, treatment adherence and teratogenicity, and healthcare providers frequently counsel women to consider termination of pregnancy in this context.[5] Provision of high-quality family planning services for affected women is therefore vital.

\section{Why was change needed?}


The WHO's "Field Guide" for the management of MDR-TB, a practical manual intended for health facility workers in low-resource settings, stipulates that reliable contraception preferably injectable - should be used by all affected women of reproductive age.[6] Combined with the rapid upscaling of bedaquiline in the South African National Tuberculosis Programme, this prompted us to investigate rates of contraceptive use in female patients enrolled in our district hospital's decentralised MDR-TB programme in Estcourt, KwaZulu-Natal. The medical records of all 56 female patients aged 13-50 commenced on MDR-TB treatment in our programme in 2016 were audited to assess compliance with WHO recommendations. Results are shown in Table 1:

Table 1: Contraceptive use and pregnancy rates in all female patients aged 13-50 initiated on the Estcourt Hospital MDR-TB treatment programme in 2016 (Cycle 1)

\begin{tabular}{|l|l|}
\hline Total & 56 \\
\hline Mean age at initiation & $29.3($ range 13-50) \\
\hline HIV seropositivity & $34(73.9 \%)$ \\
\hline Transferred out or lost to follow-up & 10 \\
\hline Complete data available & 46 \\
\hline $\begin{array}{l}\text { Contraception started prior to referral for MDR-TB } \\
\text { treatment }\end{array}$ & $11(23.9 \%)$ \\
\hline $\begin{array}{l}\text { Contraception started at the time of MDR-TB treatment } \\
\text { initiation }\end{array}$ & $0(0 \%)$ \\
\hline Pregnancy during treatment & $3(6.5 \%)$ \\
\hline Pregnancy outcome & $\begin{array}{l}2 \times \text { termination of pregnancy } \\
1 \times \text { uncomplicated Caesarean } \\
\text { section at full term }\end{array}$ \\
\hline
\end{tabular}

MDR-TB = multidrug-resistant tuberculosis; HIV = human immunodeficiency virus.

We were concerned that low baseline rates of contraceptive use in our population could lead to delay in enrolment into a bedaquiline programme and high rates of pregnancy during MDR-TB treatment, leading to materno-fetal morbidity and increased requirement for termination of pregnancy.

Despite liberal abortion legislation, women seeking termination of pregnancy in South Africa frequently face discrimination and poor access to services. Although at least two-thirds of pregnancies in KwaZulu-Natal are unintended, over $50 \%$ of abortions in the province occur 
outside a designated health facility[7] and almost $25 \%$ of maternal deaths from septic miscarriage in 2014-2016 occurred as a direct consequence of unsafe abortion.[8]

We therefore conducted a project that aimed to integrate contraception into the standardised treatment initiation pathway for MDR-TB, increase usage of long-acting injectable contraceptives among women with MDR-TB, and increase the proportion of female MDR-TB patients eligible for bedaquiline therapy. Given that this was a service delivery improvement project in which contraception was provided as part of the routine package of MDR-TB care (as stipulated in both WHO and national treatment guidelines)[4,6], ethical approval and patient consent were not considered necessary. All patient data was anonymised during the audit process.

\section{How did we go about implementing change?}

During November 2016 we integrated contraceptive services into routine MDR-TB outpatient care by liaising with the hospital pharmacy and procuring a supply of depotmedroxyprogesterone acetate (DMPA) for the MDR-TB unit. Eight specialist MDR-TB nurses were trained in family planning counselling and administration of DMPA by doctors and specialist nurses from the gynaecology department.

Any patient who wished to conceive or who became pregnant during MDR-TB treatment was referred to a tertiary hospital for individualised management.

\section{What outcomes resulted from the change in practice?}

A second audit cycle of the same outcome measures in was conducted in all 58 female patients aged 13-50 commenced on MDR-TB treatment in our programme in January-October 2017. Proportions of categorical variables were compared using Pearson's Chi-squared* and Fisher's exact** tests as appropriate. Results are shown in Table 2:

Table 2: Contraceptive use and pregnancy rates in all female patients aged 13-50 initiated on the Estcourt Hospital MDR-TB treatment programme in 2016 (Cycle 1) and in JanuaryOctober 2017 (Cycle 2). 


\begin{tabular}{|l|l|l|l|}
\hline & Cycle 1 & Cycle 2 & p-value \\
\hline Total & 56 & 58 & \\
\hline Mean age at initiation & $29.3($ range 13-50) & 31.2 (range 15-44) & \\
\hline HIV seropositivity & $34(73.9 \%)$ & $23(74.2 \%)$ & \\
\hline Complete data available & 46 & 31 & $0.1641^{*}$ \\
\hline $\begin{array}{l}\text { Contraception started } \\
\text { prior to referral for } \\
\text { MDR-TB treatment }\end{array}$ & $\begin{array}{l}11(23.9 \%) \\
10 \mathrm{DMPA} \\
1 \text { implant }\end{array}$ & $\begin{array}{l}12(38.7 \%) \\
\bullet 11 \mathrm{DMPA} \\
1 \text { bilateral tubal } \\
\text { ligation }\end{array}$ & \\
\hline $\begin{array}{l}\text { Contraception started at } \\
\text { the time of MDR-TB } \\
\text { treatment initiation }\end{array}$ & $0(0 \%)$ & $\begin{array}{l}12(38.7 \%) \\
-12 \mathrm{DMPA}\end{array}$ & $<0.0001^{*}$ \\
\hline $\begin{array}{l}\text { Total number of women } \\
\text { who were on long- } \\
\text { acting injectable } \\
\text { contraceptives by the } \\
\text { time their MDR-TB } \\
\text { treatment was initiated }\end{array}$ & $11(23.9 \%)$ & $24(77.4 \%)$ & $<0.0001^{*}$ \\
\hline $\begin{array}{l}\text { Pregnancy during } \\
\text { treatment }\end{array}$ & $3(6.5 \%)$ & $0(0 \%)$ & $0.2690^{* *}$ \\
\hline
\end{tabular}

MDR-TB = multidrug-resistant tuberculosis; HIV = human immunodeficiency virus; $D M P A=$ depot-medroxyprogesterone acetate

We demonstrated significant increases in: (a) the number of women being commenced on contraception at the time of their MDR-TB treatment initiation; and (b) the total proportion of women on long-acting injectable contraceptives by the time they started MDR-TB treatment. The reduction of incident pregnancies from $6.5 \%$ in Cycle 1 to $0 \%$ in Cycle 2 was encouraging and suggests that these interventions may help to prevent pregnancy in women undergoing MDR-TB treatment. There were no adverse events reported in the women who received DMPA.

\section{Was the change beneficial?}

By integrating contraceptive services into MDR-TB care, the proportion of women on injectable contraceptives by the time of MDR-TB treatment initiation increased more than 3fold, from $23.9 \%$ to $77.4 \%$ ( $\mathrm{p}<0.0001$ ). This represents a significant step towards ensuring that no female MDR-TB patient is excluded from bedaquiline therapy due to lack of reliable contraception. 


\section{Limitations}

Contraceptive choice in women infected with HIV or at high risk of acquisition is a challenging and rapidly evolving field. We had initially intended to offer the subdermal etonogestrel implant to women commencing contraception at MDR-TB treatment initiation. However, we were deterred by the powerful stigmatisation of this method in the local population: some women had experienced physical assault by their male partners when they discovered the implant, and many believed their antiretroviral therapy (ART) rendered it ineffective. Accumulating evidence supports this: a recent Kenyan study of 24,560 HIV-positive women using contraceptive implants revealed a three-fold higher pregnancy rate in those taking efavirenz-based vs. nevirapine-based ART.[9] Although our patients had all been switched from efavirenz- to nevirapine-based ART as this is a requirement for bedaquiline eligibility, many retained their beliefs that any ART would invalidate contraceptive efficacy of the implant.

We therefore offered DMPA as the first-line option for women in our study. It had high acceptability to the target population and concerns that it might increase the risk of HIV acquisition were not substantiated in the recent large, randomised ECHO trial.[10]

Further limitations include small cohort sizes and the inability to demonstrate sustained improvements across longer time periods. Future work should focus on widening the choice of contraceptives available and addressing the stigma surrounding certain methods.

\section{Advice to others considering change}

We advise others considering similar intervention to familiarise themselves with attitudes to different contraceptive methods in the target community, to avoid waste of resources and potential patient harm. We appreciate the limitations of this small evaluation but encourage others to embark on similar service integration projects, ensuring that they maintain close collaboration with patients, nurses and managerial teams across community-based and hospital stakeholder sites.

Box 1: Key Messages 
- Reliable long-acting contraception is mandatory for female MDR-TB patients to secure eligibility for bedaquiline, which reduces duration of MDR-TB treatment from 20-24 to 9-12 months

- Low baseline rates of contraceptive use, high frequency of unplanned pregnancies and social stigma around certain long-acting contraceptive methods threaten female patients' eligibility for bedaquiline

- Integrating family planning services into decentralised MDR-TB care improves contraceptive uptake, increases bedaquiline eligibility and alleviates the burden of multiple healthcare facility visits for patients

\section{References}

1. World Health Organisation. Global Tuberculosis Report 2018. Geneva: World Health Organisation; 2018. Licence: CC BY-NC-SA 3.0 IGO. Available from: https://www.who.int/tb/publications/global_report/en/, accessed 21 March 2019

2. Gandhi NR, Moll A, Sturm AW et al. Extensively drug-resistant tuberculosis as a cause of death in patients co-infected with tuberculosis and HIV in a rural area of South Africa. Lancet 2006;368(9547):1575-80

3. Hirasen K, Berhanu R, Evans D, Rosen S, Sanne I, Long L. High rates of death and loss to follow-up by 12 months of rifampicin resistant TB treatment in South Africa. PLoS One 2018;13(10):e0205463

4. World Health Organisation. Treatment guidelines for drug-resistant tuberculosis, 2016 update (October 2016 revision). World Health Organisation; 2016. Available from: http://apps.who.int/iris/bitstream/10665/250125/1/9789241549639-eng.pdf, accessed 21 March 2019

5. Shin S, Guerra D, Rich $M$ et al. Treatment of multidrug-resistant tuberculosis during pregnancy: a report of 7 cases. Clin Infect Dis 2003;36(8):996-1003

6. World Health Organisation. Management of MDR-TB: A field guide. World Health Organisation; 2009. Available from:

http://apps.who.int/medicinedocs/documents/s21658en/s21658en.pdf, accessed 31

October 2019

7. Reddy SP, James S, Sewpaul R et al. The South African Youth Risk Behaviour Survey 2008. Cape Town: South African Medical Research Council; 2010. Available from: https://granthaskin.files.wordpress.com/2012/06/youth-risk-behaviour-survey2008 final_report.pdf, accessed 21 March 2019

8. South African National Committee for Confidential Enquiries into Maternal Deaths (NCCEMD). Saving Mothers 2014-2016: Seventh triennial report on confidential enquiries into maternal deaths in South Africa. Pretoria: Department of Health; 2018. Available from: https://www.sasog.co.za/Content/Docs/Saving_Mothers.pdf, accessed 21 March 2019. 
9. Patel RC, Onono M, Gandhi M et al. Pregnancy rates in HIV-positive women using contraceptives and efavirenz-based or nevirapine-based antiretroviral therapy in Kenya: a retrospective cohort study. Lancet HIV 2015;2(11):e474-82

10. Evidence for Contraceptive options and HIV Outcomes (ECHO) Trial Consortium. HIV incidence among women using intramuscular depot medroxyprogesterone acetate, a copper intrauterine device, or a levonorgestrel implant for contraception: a randomised, multicentre, open-label trial. Lancet 2019;394(10195):303-313

\section{Acknowledgements}

None

\section{Competing interests}

None declared

\section{Funding}

None 